\title{
Conservative Management of Patent Ductus Arteriosus in Preterm Infants
}

\author{
M.C. Lelong Tissier, A. Benoit, M. Dehan, M. Vial, J.-C. Ropert and Y. Dupic \\ Hôpital Antoine Béclère, Clamart, France
}

\begin{abstract}
We report our experience of medical treatment, chiefly based on prolonged artificial ventilation, of 33 preterm infants with PDA and heart failure whose survival rate was $88 \%$. All of them had clinical criteria used by others to indicate surgical ligation of the ductus arteriosus.

This conservative approach seems to give better results than surgical ligation, despite a high frequency of bronchopulmonary dysplasia among survivors.
\end{abstract}

Key words: Patent ductus arteriosus Heart failure,Preterm, Medical treatment. Broncho-pulmonary dysplasia.

\section{Introduction}

Patent ductus arteriosus (PDA) frequently occurs in preterm infants with respiratory distress (R.D.). Many reports have recommended surgical ligation of the ductus arteriosus when it is the cause of heart failure. Most of these reports have been reviewed by Rittenhouse [13] in 1976: depending on the series, the death rate varies from 18 to 50 per cent. Using the same clinical criteria as those used by different authors in proposing candidates for surgical ligation, we have found in our department 33 patients with PDA and heart failure who should have undergone surgery [1]. Since we did not undertake any surgical ligation and because we obtained an $88 \%$ survival rate, we decided it necessary to analyse our results retrospectively [8].

\section{Patients and Method}

From August 1973 to October 1976, 447 preterm infants with R.D. were admitted into the neonatal intensive care unit. 248 of these infants (53\%) had to be intubated for mechanical ventilation using a RPN (Pesty) ventilator.

The diagnosis of PDA was made according to the following clinical signs: systolic or continous infra-clavicular and precordial murmur, bounding pulses and hy- peractive precordium. The diagnosis of heart failure was retained in the presence of tachycardia, excessive weight gain, cardiomegaly, pulmonary hypervascularity and / or pulmonary oedema.

Pulmonary sequelae were considered as bronchopulmonary dysplasia (B.P.D.) when X-Ray evidence was patent, especially the juxta-position of emphysematous and atelectatic areas in the two lungs [12].

For this retrospective study we selected 33 patients who should have undergone surgical ligation, according to the criteria used by different authors: frequent apnoeic spells associated with bradycardia, rising $\mathrm{PCO} 2$ and falling $\mathrm{Pa} 02$, inability to wean the patients from mechanical ventilation or need to re-ventilate, these signs being refractory after several days of medical treatment $[3,13]$. Despite these signs, we treated all the cases conservatively with Digitoxin (12 to $20 \gamma / \mathrm{kg} /$ day), fluid restriction ( 80 to $120 \mathrm{ml} / \mathrm{kg} /$ day), diuretics (Furosemide $1 \mathrm{mg} / \mathrm{kg} /$ injection), prolonged mechanical ventilation with increased Fi02 and physiotherapy [15]. Since none of our patients were proposed for surgery, we analyse these observations in order to assess the effectiveness of this supportive therapy and to compare our results with the surgical ones.

\section{Results}

Among the 447 preterm infants with R.D. (Tab. 1), the diagnosis of PDA was made 55 times $(12,5$ percent); the overall mortality was 17.5 per cent in the group of babies less than 28 weeks of gestation, to 8.5 per cent in the 35 . 36 weeks group. Most of the deaths ( 69 per cent) occured during the first week of life (53 cases), and were unrelated to cardio-pulmonary failure from PDA. The late mortality (survival of at least one week) concerns 24 babies (31 per cent of the deaths), of whom two had a PDA without failure and were not included in the present survey (Table 2). Pulmonary sequelae (B.P.D.) concerned 29 infants (6.5 per cent): 17 of them had PDA of which 13 had heart failure (Fig. 3 ). 
Table 1. Distribution of P.D.A. and deaths according to gestational age among 447 preterm babies with R.D.

\begin{tabular}{lcccccc}
\hline Gestational Age & No. of cases & \multicolumn{2}{c}{ No. of P.D.A. (\%) } & \multicolumn{2}{c}{ Death \% } \\
\hline 28 weeks & 22 & 6 & $(27 \%)$ & 15 & $(65 \%)$ \\
\hline $29-32$ weeks & 109 & 27 & $(25 \%)$ & 23 & $(21 \%)$ \\
\hline $33-34$ weeks & 155 & 10 & $(6.4 \%)$ & 25 & $(16 \%)$ \\
\hline $35-36$ weeks & 161 & 12 & $(7.4 \%)$ & 14 & $(8.6 \%)$ \\
\hline total & 447 & 55 & $(12.3 \%)$ & 77 & $(17.2 \%)$ \\
\hline
\end{tabular}
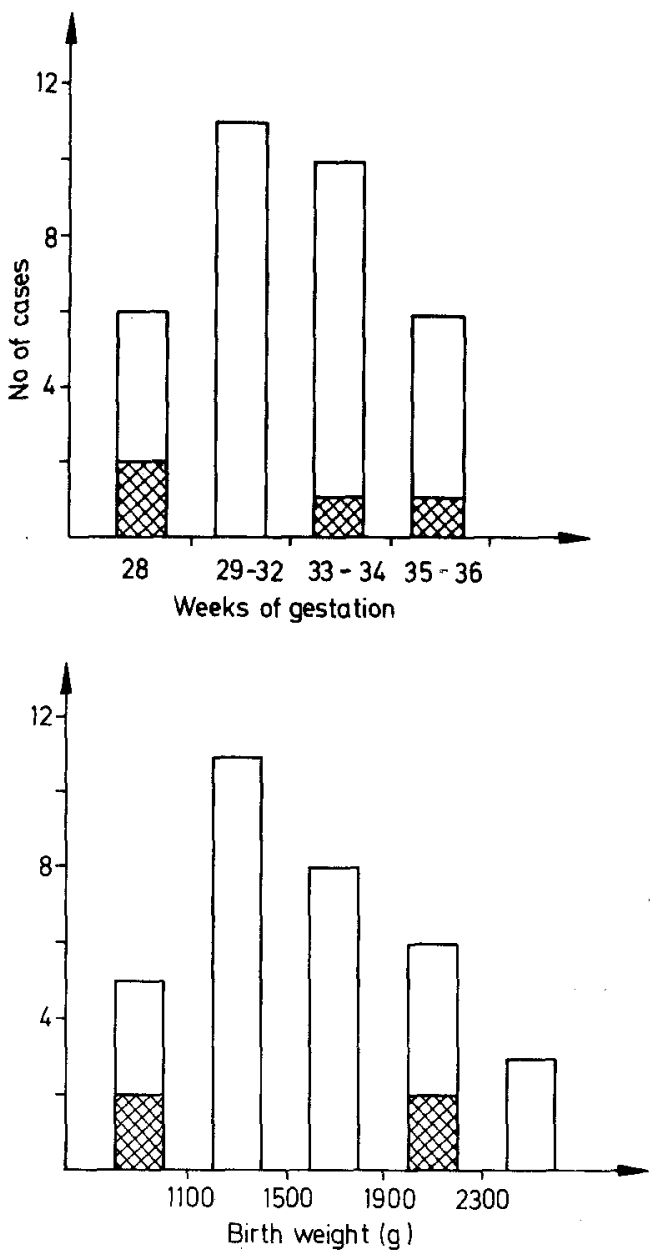

Fig. 1. Distribution of 33 preterm infants with PDA and heart failure according to gestational age and birth weight (boxes with slashes represent deaths)

Figure 1 shows the distribution of the 33 preterm infants with P.D.A. and heart failure according to gestational age and birth weight (means 31 weeks and $1665 \mathrm{~g}$ ). Because of their initial R.D. 32/33 infants were artificially ventilated: 26 babies required an $\mathrm{FiO} 2<0.6$ for an aver-
Table 2. Causes of death among 447 R.D.

\begin{tabular}{|c|c|c|c|}
\hline \multicolumn{4}{|c|}{$\begin{array}{l}77 \text { Deaths among } \\
447 \text { preterm }(17.2 \%)\end{array}$} \\
\hline $\begin{array}{l}\text { Early Deaths } \\
53 / 77: 69 \%\end{array}$ & & $\begin{array}{l}\text { Late Deaths } \\
24 / 77: 31 \%\end{array}$ & \\
\hline Intraventricular hemorrage & 27 & Neurologic alteration & $7\left(1^{a}\right)$ \\
\hline $\begin{array}{l}\text { Critical condition } \\
\text { when admitted }\end{array}$ & 9 & BPD & $5\left(1^{a}, 2^{b}\right)$ \\
\hline Septicemia & 7 & Septicemia & $4\left(1^{b}\right)$ \\
\hline RDS & 4 & $\begin{array}{l}\text { Necrotizing } \\
\text { enterocolitis }\end{array}$ & $3\left(1^{b}\right)$ \\
\hline \multirow[t]{3}{*}{ Others causes } & 6 & Malformations & 3 \\
\hline & 53 & Miscellaneous & 2 \\
\hline & & & 24 \\
\hline
\end{tabular}

a PDA

b PDA and heart failure

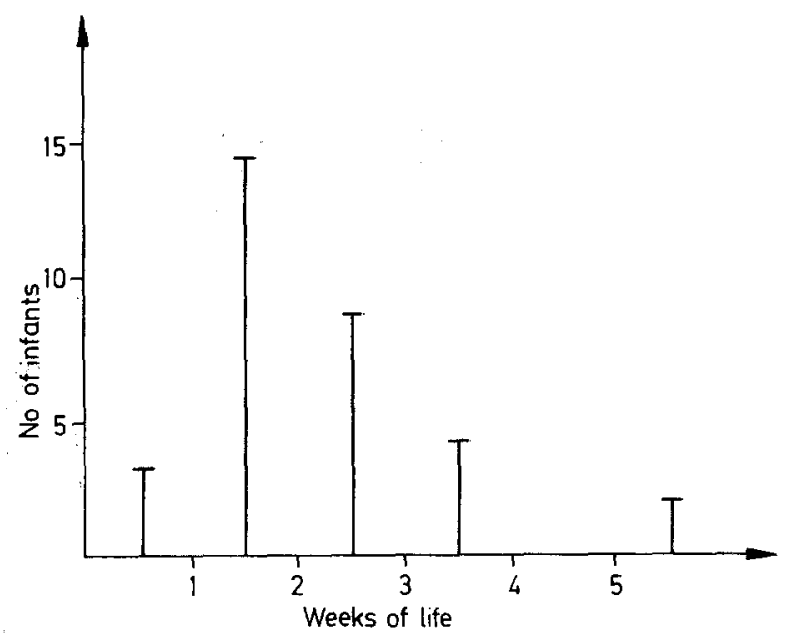

Fig. 2. Age of the infants when failure developed

age of 3 days. Signs which should have led to the decision of surgical ligation appeared mostly at the beginning of the second week of life (Fig. 2). All these babies were managed conservatively requiring a total of 1664 days of respiratory support, among which 1210 days was for the survivors: infants without pulmonary sequelae were artificialy ventilated an average of 24 days, whereas infants with BPD were ventilated an average of 70 days.

Four babies died (12 per cent mortality): two small preterms (birth weight less than $1100 \mathrm{~g}$ ) died at one month from necrotizing enterocolitis with septicemia. The two others died at 6 months of age after interruption of mechanical ventilation, justified by major neurological abnormalities with microcephaly. Both infants had been artifically ventilated since birth. The autopsies showed marked broncho-pulmonary dysplasia and right ventricular hypertrophy. 
Table 3. Evolution of 11 patients suffering from BPD

\begin{tabular}{|c|c|c|c|}
\hline Name & G.A. / BW & $\begin{array}{l}\text { Ventilator } \\
\text { duration }\end{array}$ & Follow up \\
\hline All. Lau. & $31 \mathrm{~W} / 1650 \mathrm{~g}$ & 43 days & Radiologic scars only \\
\hline Win. aAng. & $33 \mathrm{~W} / 1800 \mathrm{~g}$ & 71 days & Many hospitalisations for bronchiolitis up to 2 years \\
\hline Dup. Nat. & $28 \mathrm{~W} / 1100 \mathrm{~g}$ & 60 days & One hospitalisation up to 15 months of age \\
\hline Fer. Car. & $30 \mathrm{~W} / 1600 \mathrm{~g}$ & 18 days & No follow up \\
\hline Gue. Fre. & $30 \mathrm{~W} / 1340 \mathrm{~g}$ & 5 months & No further hospitalisation. Thoracic deformation ( 2 years old) \\
\hline Van Ter. & $35 \mathrm{~W} / 1820 \mathrm{~g}$ & 20 days & No further hospitalisation ( 10 months old) \\
\hline Bon. Yas. & $31 \mathrm{~W} / 1100 \mathrm{~g}$ & 65 days & 3 days hospitalisation for bronchiolitis \\
\hline Dia. ${ }^{\text {a Fer. }}$ & $32 \mathrm{~W} / 1570 \mathrm{~g}$ & 5 months & $\begin{array}{l}\text { Prolonged hospitalisation. Improving neurologic } \\
\text { impairment at } 18 \text { months old }\end{array}$ \\
\hline Nic. a Nic. & $27 \mathrm{~W} / 1180 \mathrm{~g}$ & 60 days & $\begin{array}{l}\text { Many hospitalisations for bronchiolitis. Improving } \\
\text { neurologic impairment at } 24 \text { months }\end{array}$ \\
\hline Boe. Jul. & $30 \mathrm{~W} / 1300 \mathrm{~g}$ & 3 months & No further hospitalisation \\
\hline Pir. O & $28 \mathrm{~W} / 1150 \mathrm{~g}$ & 50 days & No further hospitalisation \\
\hline
\end{tabular}

a 3 patients have severe pulmonary sequelae

Table 4. Mean birth weight of dead infants in different series compared with mean birth weight of the corresponding series

\begin{tabular}{lrrrr}
\hline Author & $\begin{array}{l}\text { No. of } \\
\text { Cases }\end{array}$ & $\begin{array}{l}\text { Average } \\
\text { Birth } \\
\text { weight(g) }\end{array}$ & $\begin{array}{l}\text { Percentage } \begin{array}{l}\text { Average } \\
\text { of Death \% }\end{array} \\
\text { Birth weight } \\
\text { of Deaths(g) }\end{array}$ \\
\hline Gay et a1. [4] & 45 & 1400 & 33 & 1400 \\
Horsley et al. [6] & 9 & 1200 & 44 & 1300 \\
Murphey et al. [9] & 10 & 1400 & 50 & 1310 \\
Neal et al. [10] & 5 & 1260 & 40 & 1250 \\
Nelson et al. [11] & 32 & 1020 & 40 & 975 \\
Rittenhouse et al. [13] & 11 & 1325 & 18 & 1000 \\
Zachman et al. [17] & 27 & 1400 & 33 & 1150 \\
Others Series [13] & 61 & - & 36 & - \\
Total & 200 & 1250 & 36 & \\
Authors' Series & 33 & 1665 & 12 & 1600 \\
\hline
\end{tabular}

Twenty nine infants survived (88\%) with a follow-up period of from 12 to 43 months. Eighteen of them $(62 \%)$ recovered without clinical or radiological damage, but eleven (38\%) stiffered from BPD (Table 3). In three cases, pulmonary \& fuelae with recurrent bronchiolitis were judged as seric s and in eight cases as mild, without clinical impairm

\section{Disscussion}

The first question concerning this retrospective study is to know if the series is comparable to surgical ones. If all the surgical series are taken together, the average gestational age ( 29.5 weeks) and the average birth weight $(1250 \mathrm{~g})$ for 200 infants, are lower than those of our population (31 weeks and $1665 \mathrm{~g}$, respectively); but, the mean birth weight of deceased infants is usually the same

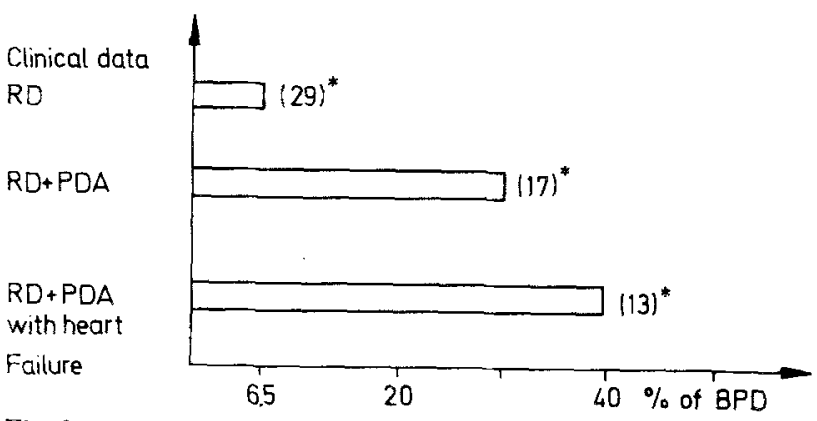

Fig. 3. PDA and BPD occurence. (TP) * $n b$ of infants

as the mean weight of corresponding series, as in our ( $\mathrm{Ta}$ ble 4). Moreover, if we had limited our selection to infants weighing less than $1500 \mathrm{~g}$, our results would not have been different (Fig. 1). Likewise, we can question the accuracy of our diagnosis of P.D.A and heart failure. We did not use aortography [7] nor echocardiography [14] to confirm clinical diagnosis; but authors who have such methods at their disposal consider they are not essential for determining the necessity of ligation in their patients [13]. Therefore, based upon the same clinical criteria, we can reasonably conclude that our series is comparable to surgical series and that our 33 babies would most probably have been operated on elsewere.

Our results show a low mortality rate $(12 \%)$ in compa. rison to that of surgical patients (18 to $50 \%$ as reviewed by Rittenhouse [13]. We do not believe ourselves to have underestimated the role of PDA in the mortality of our population: first because $69 \%$ are early deaths (less than one week of age), unrelated to PDA; second because heart failure occurred mostly after the seventh day of life and third because late death (more than one week of age) were due to causes other than PDA except in the 4 above described patients. These latter 4 deaths may be related to haemodynamic consequences of the $\mathrm{DA}$, but were not directly induced by heart failure. 
In the surgical series mortality is mostly ascribed to two main causes: extreme prematurity $[2,11]$ and respiratory insufficiency $[2,11,17]$. The aim of surgery is to remove the shunt in order to prevent deterioration of the pulmonary function [4], because nearly two thirds of deaths, in the cases recorded in the literature, are due to progressive respiratory insufficiency [13]. But should we propose surgery for a preterm baby with cardiorespiratory failure due to PDA because he is threatened by developing respiratory insuffiency? Or should we keep the same baby on prolonged medical conservative treatment? In term of mortality, our choice is the latter because of our better results. Even early ligation does not diminish mortality rate $(37 \%)$, when there is a decreasing $B P D$ rate [16].

Among the 29 surviving babies, we found a high frequency of BPD (38\%) (Table 3). Three cases are judged as severe and eight as mild, the main criteria of the diagnosis being radiologic. We recall that, in addition, two of the dead infants showed anatomic evidence of BDP. It is nearly impossible to compare our cases with BPD cases after surgical ligation. Very few surgeons analyse the pulmonary sequelae of the survivors. We found only two reports in which BPD occurence is discussed $[4,16]$ and it is from the point of view of BPD factors only. Gay [4] analyses ten severe BPD of which nine died. Mild BPD cases, as sequel, are not analysed. Whisitt [16], in his abstract, reports a $25 \%$ occurence of BPD in a series of early ligation and $55 \%$ in a series of late ligation, but we do not know if the BPD concerned deceased or living babies. Comments indicate that there is a correlation between the duration of ventilation and the occurence of $B P D$, as in our series.

Figure 3 illustrates the importance of PDA in the incidence of BPD among survivors of R.D. in preterms: nearly 45 per cent of our BPD cases are associated with cardio-respiratory failure caused by PDA. Probably the duration of artificial ventriculation plays a part as is indicated by the difference in the mean intubation duration for patients with BPD and without BPD, in our and in surgical series $[4,16]$. However one must not forget the initial gravity of our R.D., reflected by the importance of oxygen supply, at the origin of prolonged respiratory support. In fact, the pulmonary sequelae improved and only 3 of the babies had pulmonary problems at 2 years of age, the other 8 showing only radiological alterations without clinical discomfort. However, one cannot deny the numerous problems that are raised in the nursing and in the maintenance of small and fragile babies for such a prolonged time under artifical ventilation. But, it is feasible and worthwile if we simply consider the enhanced survival rate of the babies in our charge.

In view of these results, one can support the hypothesis that an early closure of large shunting PDA in preterms with RD is beneficial. But, instead of surgical procedure, one should wait for promising results afforded by inhibitors of anti protaglandins synthesis $[5,3]$.

\section{References}

1. Benoit, A.: Le canal artériel mal toléré chez le prématuré en detresse respiratoire. A propos de 33 observations. Thèse Paris 1978 (à paraître)

2. Edmunds, L.H., Gregory, G.A., Heymann, M.A., Kitterman, J.A., Rudolph, A.M., Tooley, S.H.: Surgical closure of the ductus arteriosus in premature infant. Circulation 48,856 (1973)

3. Friedman, W.F., Hirschklau, M.J., Printz, M.P., Pitlick, P.T., Kirkpatrick, S.I.: Pharmacological closure of patent ductus arteriosus in the premature infant. N. Engl. J. Med. 295, 526 (1976)

4. Gay, J.H., Daily, W.J.R., Meyer, B.H.P., Trump, D.S., Cloud, D.I., Molthan, M.E.: Ligation of the patent ductus arteriosus in premature infants: report of forty-five cases. J. Pediat. Surg. 8, 677 (1973)

5. Heymann, M.A., Rudolph, A.M., Silverman, N.H.: Closure of the ductus arteriosus in premature infants by inhibition of prostaglandin synthesis. N. Engl. J. Med. 295, 530 (1976)

6. Horsley, B.L., Terberg, D.B., Allen, A.C., Zuberbuhler, J.R., Bahnson, H.T.: Respiratory distress from patent ductus arteriosus in the premature newborn. Ann. Surg. 177, 806 (1973)

7. Lachman, R.S., Pfisterer, W.F.; Herman, M.W., Prewitt, I.H., Maenza, R., Colle, S., Thibeault, D.W.: The P.D.A. syndrome in preterm infants. The technique of single film aortography and other diagnostic radiographic criteria. Ann. Radiol. 20, 31 (1977)

8. Lelong - Tissier, M.C., Dehan, M.: Le traitement médical du canal artériel mal tolêré chez le prématuré: une alternative encore valable? Intens. Care Med. 3, 178 (1977) (abstract)

9. Murphy, D.A., Outerbridge, E., Stern, I., Karn, G.M., Jegier, W., Rosales, J.: Management of premature infants with patent ductus arteriosus. J. Thorac. Cardiovasc. Surg. 67, 221 (1974)

10. Neal, W.A., Bessinger, F.B., Hunt, C.E., Lucas, R.V.: Patent ductus arteriosus complicating respiratory distress syndrome. J. Pedit. 86, 127 (1975)

11. Nelson, R.J., Thibeault, D.W., Emmanouilides, G.C., Lippmann, M.: Improving the results of ligation of patent ductus arteriosus in small preterm infants. J. Thorac. Cardiovasc. Surg. 71, $169(1976)$

12. Northway, W.H., Rosan, R.C.: Radiographic features of pulmonary oxygen toxicity in the newborn: bronchopulmonary dysplasia. Radiology 91, 49 (1968)

13. Rittenhouse, E.A., Doty, D.B., Lauer, R.M., Ehrenhafi, J.L.,: Patent ductus arteriosus in premature infants. Indications for surgery. J. Thorac. Cardiovasc. Surg. 71, 187 (1976)

14. Silverman, N.H., Lewis, A.B., Heymann, M.A., Rudolph, A.M.: Echocardiographic assessment of ductus arteriosus shunt in premature infants. Circulation 50, 821 (1974)

15. Vincon, C.: Une méthode de kinésithérapie respiratoise appliquée à un service de réanimation néonatale. Entretiens de Bichat, J. de Rééducation 24.9.76

16. Whitsitt, L.S., Baden, M., Traugott, R.C., Treasure, R.: Early ligation of P.D.A., effect on B.D.P. and post-operative ventilator time. Ped. Res. 142, April 1977 (abst.)

17. Zachman, R.D., Steinmetz, G.P., Bothman, R.J., Graven, S.N., Ledbetter, M.K.: Incidence and treatment of the patent ductus arteriosus in the ill premature neonate. Am. Heart. J. 87, 697 (1974)

Dr. M.-C. Lelong-Tissier

Service de réanimation néonatale (Pr. J.C. Gabilan)

Hôpital Antoine Béclée

rue Porte de Trivaux

F-92141 Clamart

France 